\title{
Dynamics Of Changes In Anthropometric Indices In Patients With Generalized Periodontitis Of I-II Degree On The Background Of Injection Osteoplastic Therapy
}

Research Article

Bezrukov S. G. ${ }^{1}$, Saenko T.S ${ }^{2}$, Saenko V.L. ${ }^{3}$, Yelcheva L. A. ${ }^{4}$

${ }^{1}$ Head of the Department of Surgical Dentistry and Maxillofacial Surgery, Professor, Faculty of Dentistry of the Medical Academy named after S. I. Georgievsky of Vernadsky CFU, Simferopol, 95000, Russian Federation.

${ }^{2}$ Assistant of the Department of Theraputical Dentistry, Faculty of Dentistry of the Medical Academy named after S. I. Georgievsky of Vernadsky CFU, Simferopol, 95000 Russian Federation.

${ }^{3}$ Assistant of the Department of Surgical Dentistry and Maxillofacial Surgery, Faculty of Dentistry of the Medical Academy named after S. I. Georgievsky of Vernadsky CFU,Simferopol, 95000 Russian Federation.

${ }^{4}$ Senior teacher of the Department of Surgical Dentistry and Maxillofacial Surgery, Faculty of Dentistry of the Medical Academy named after S. I. Georgievsky of Vernadsky CFU,Simferopol, 95000 Russian Federation.

\section{Abstract}

The dynamics of anthropometric indicators in patients with generalized periodontitis of I-II degree confirms the effectiveness of injectable use of osteoplastic materials (for example, PRP and Collapan C) in the complex treatment of this pathology. The most pronounced local augmentation was noted in the 2 nd main group, where there were significant differences in alveolar bone volume indices by the 30 -day observation period $(\mathrm{P} 1<0.05)$, then they continued their growth by 3, 6-12 months (P1 $<0.05, \mathrm{P} 2<0.05, \mathrm{P} 3<0.05)$. In our opinion, the positive osteoplastic therapeutic effect detected in patients in this group is due to the complementary properties of PRP-gel and the drug Collapan C, which together demonstrate osteoinductive and osteoconductive properties, manifested in presence of the release of silver ions, which has a local antiseptic and anti-inflammatory effect. All this, together, creates optimal conditions for preserving and restoring the volume of the alveolar bone. Patients in the I-th main group also showed a positive result, where, despite the absence of a noticeable increase in bone tissue, its volume was preserved, which is explained by the pronounced osteoinductive and immunocorregulating properties of autoplasm with an increased platelet content.

In patients in the control group, the process of gradual loss of the alveolar bone continued after treatment, which had a shortterm positive result.

The data of anthropometry are confirmed by the results of radiography.

Keywords: Anthropometry of the Jaws; Osteoplastic Materials; Collapan C; PRP; Treatment of Generalized Periodontitis of I-II Degree.

\section{Introduction}

The morbidity rate of periodontal diseases continues to be high. In this regard, the problem of the effectiveness of methods of treatment of this pathology remains important.

In modern surgical dental practice, osteoplastic materials are ac- tively used. Platelet-rich blood plasma (PRP) is increasingly used to optimize regeneration processes $[1,2,5]$. It is widely used during osteoplastic operations (sinus lifting, augmentation of the alveolar process), for the treatment of the operating area before dental implantation, etc. [5, 8]. It was found that PRP has a significant osteoinductive effect. At the same time, it is known that in the complex treatment of generalized periodontitis, it is advisable

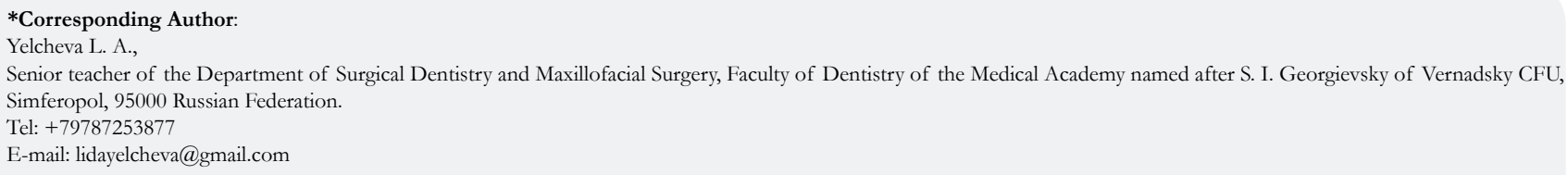

Citation: Bezrukov S. G., Saenko T.S, Saenko V.L., Yelcheva L. A. Dynamics Of Changes In Anthropometric Indices In Patients With Generalized Periodontitis Of I-II Degree On The Background Of Injection Osteoplastic Therapy. Int J Dentistry Oral Sci. 2022;9(1):5217-5222. doi: http://dx.doi.org/10.19070/2377-8075-220001046

Copyright: Yelcheva L. $\mathbf{A}^{\circ}$ 2022. This is an open-access article distributed under the terms of the Creative Commons Attribution License, which permits unrestricted use, distribution and reproduction in any medium, provided the original author and source are credited. 
to use osteoconductors $[4,7,9,10]$, which allow increasing the volume of bone tissue. Recently, the range of domestic synthetic osteoplastic (osteoconductive) drugs has expanded in the medical market. One of them is the silver-containing material Collapan C.

The purpose of the study. To keep track of the changes in anthropometric indicators dynamic in patients in the comparison groups during the complex treatment of generalized periodontitis of I-II degree, including injection of osteoplastic materials.

\section{Materials And Methods Of Research}

The patients were treated on an outpatient conditions. The results of clinical indices were analyzed during the treatment and examination of 120 patients of both sexes aged 25 to 50 years ( 40 patients in the 1 st main group, 40 in the 2 nd main group and 40 in the control group).

In the control group, the traditional complex treatment of generalized periodontitis of the I - II degrees was performed with the injection of aloe extract into soft tissues along the muco-gingival line in the projection of the causal teeth [3].

In the first main group, the traditional treatment was supplemented with injection point subcostal and supra-periosteal injection of PRP into periodontal tissues (at the rate of $0.3-0.5 \mathrm{ml}$ in the projection of one tooth).

In the second main group, along with complex treatment, injectable combined osteoplastic therapy of periodontal tissues with PRP and a suspension of the drug Collapan $C$ was performed, which were injected separately pinpointly into periodontal tissues at the rate of $0.3 \mathrm{ml}$ in the projection of one dental segment.

Infiltration anesthesia with $0.5 \%$ lidocaine solution was used for anesthesia.

Anthropometric measurements of the size of the alveolar processes were performed in the transversal and sagittal directions before injection therapy, as well as 1, 3, 6, and 12 months after it.
The parameters of the vertical alveolar ridge were determined by measurements carried out directly in the oral cavity using a wire probe (cross-section diameter- $0.5 \mathrm{~mm}$ ) and a medical caliper. To carry out measurements, a wire probe was installed on the chewing (cutting) surfaces of the teeth (the level of the occlusal surface), limiting the defect of the dentition. Using a measuring caliper, the distance between the surface of the probe and the mucosa of the alveolar ridge in the area of the maximum depression was determined $[2,6]$.

Horizontal measurements of the alveolar process were also evaluated using measurements carried out with a measuring caliper. The measurements were carried out in the middle of the defect zone of the dentition or in the narrowest part of the alveolar process. The contact of the mucous membrane and the working parts of the instrument was carried out by retreating 5-6 $\mathrm{mm}$ from the muco-gingival lines, without exerting pressure on the mucous membrane.

All measurements were carried out three times and the arithmetic mean was calculated.

\section{Results and Discussions}

Measurements were carried out separately for each group of teeth (in the projection of premolars and molars), as well as separately for the upper and lower jaws. Before injection therapy, the average values $(\mathrm{M} \pm \mathrm{m})$ of height and width on the upper jaw were $6.95 \pm$ $0.15 \mathrm{~mm}$ and $15.20 \pm 0.17 \mathrm{~mm}$, respectively. On the lower jaw, the values were-7.23 $\pm 0.16 \mathrm{~mm}$ and $13.44 \pm 0.19 \mathrm{~mm}$.

1 month after the therapy, the indicators increased slightly in patients in the control group, but there were no significant differences (P1>0.05), as evidenced by the persistence of weakly expressed inflammatory phenomena in the periodontium. During this observation period, the distance to the crest of the alveolar process of the upper jaw averaged $7.14 \pm 0.18 \mathrm{~mm}$, and its width was $15.56 \pm 0.19 \mathrm{~mm}$. On the lower jaw, the height index was 8.08 $\pm 0.14 \mathrm{~mm}$, and the width was $14.09 \pm 0.16 \mathrm{~mm}$ (Table 1$)$.

Table 1. The average values of the height and width of the alveolar process in the projection of the premolars and molars of the upper and lower jaws (in $\mathrm{mm}$ ) in the control group at different observation periods.

\begin{tabular}{|c|c|c|c|c|}
\hline \multirow[b]{2}{*}{ Measurement dates } & \multicolumn{2}{|c|}{ Upper jaw } & \multicolumn{2}{|c|}{ Lower jaw } \\
\hline & $\begin{array}{c}\text { height to the } \\
\text { ridge }{ }^{1}(\mathrm{~mm}) \\
n=18 \\
M \pm m\end{array}$ & $\begin{array}{c}\text { ridge } \\
\text { width(mm) } \\
\mathrm{n}=18 \\
\mathrm{M} \pm \mathrm{m}\end{array}$ & $\begin{array}{c}\text { height to the } \\
\text { ridge }^{1}(\mathrm{~mm}) \\
\mathrm{n}=18 \\
\mathrm{M} \pm \mathrm{m}\end{array}$ & $\begin{array}{c}\text { ridge } \\
\text { width(mm) } \\
\mathbf{n}=18 \\
\mathrm{M} \pm \mathrm{m}\end{array}$ \\
\hline Before injection therapy $(n=40)$ & $6.95 \pm 0.15$ & $15.20 \pm 0.17$ & $7.23 \pm 0.16$ & $13.44 \pm 0.19$ \\
\hline \multirow{2}{*}{ After 1 month $(\mathrm{n}=36)$} & $7.14 \pm 0.18$ & $15.56 \pm 0.19$ & $8.08 \pm 0.14$ & $14.09 \pm 0.16$ \\
\hline & $\mathrm{P}_{1}>0.05$ & $\mathrm{P}_{1}>0.05$ & $\mathrm{P}_{1}>0.05$ & $\mathrm{P}_{1}>0.05$ \\
\hline \multirow{2}{*}{ After 3 months $(n=36)$} & $6.93 \pm 0.12$ & $15.34 \pm 0.18$ & $7.57 \pm 0.15$ & $13.64 \pm 0.17$ \\
\hline & $\mathrm{P}_{1}>0.05$ & $\mathrm{P}_{1}>0.05$ & $\mathrm{P}_{1}>0.05$ & $\mathrm{P}_{1}>0.05$ \\
\hline \multirow{2}{*}{ After 6 months $(n=36)$} & $6.89 \pm 0.14$ & $15.18 \pm 0.16$ & $7.21 \pm 0.17$ & $13.36 \pm 0.15$ \\
\hline & $\mathrm{P}_{1}>0.05$ & $\mathrm{P}_{1}>0.05$ & $\mathrm{P}_{1}>0.05$ & $\mathrm{P}_{1}>0.05$ \\
\hline \multirow{2}{*}{ After 12 months $(\mathrm{n}=36)$} & $6.76 \pm 0.16$ & $15.05 \pm 0.19$ & $6.98 \pm 0.18$ & $13.28 \pm 0.13$ \\
\hline & $\mathrm{P}_{1}>0.05$ & $\mathrm{P}_{1}>0.05$ & $\mathrm{P}_{1}>0.05$ & $\mathrm{P}_{1}>0.05$ \\
\hline
\end{tabular}

1 - the distance from the conditional line drawn through the occlusal surfaces of the teeth to the crest of the alveolar process in the area of maximum gum recession; $\mathrm{P}_{1}$ - the reliability of differences with the indicator before treatment. 
3 months after the treatment, the amount approached the baseline level $(\mathrm{P} 1>0.05)$, and after 6 months they became slightly lower than it. On the upper jaw, the average sagittal parameters (up to the crest) were $6.93 \pm 0.12 \mathrm{~mm}$, and the transversal ones were $15.34 \pm 0.18 \mathrm{~mm}$ (at P1>0.05). In the lower jaw, the dimensions of the alveolar process corresponded to $7.57 \pm 0.15 \mathrm{~mm}$ and $13.64 \pm 0.17 \mathrm{~mm}$, respectively (at P1>0.05).

1 year after injection therapy, a decrease in the volume of the alveolar bone was registered in the representatives of the control group: in the upper jaw, the analyzed values were $6.76 \pm 0.16 \mathrm{~mm}$ in height and $15.05 \pm 0.19 \mathrm{~mm}$ in width, that is, the difference, compared to the baseline level, was $-0.19 \mathrm{~mm}$ and $-0.15 \mathrm{~mm}$, respectively, in the lower jaw, these indicators were at the level of $6.98 \pm 0.18 \mathrm{~mm}(-0.25 \mathrm{~mm})$ in height and $13.28 \pm 0.13 \mathrm{~mm}(-0.16$ $\mathrm{mm}$ ) in width (at $\mathrm{P} 1>0.05)$.

The data of vertical and horizontal measurements during the entire observation period did not have significant differences (at $\mathrm{P} 1>0.05)$. This indicated that there were no any osteoplastic processes in the alveolar bone in response to the attempted injection of $1 \%$ Aloe extract, and, in addition, continued sluggish bone resorption, characteristic of the chronic course of periodontitis, was recorded.

In the 1st main group, 1 month after the injection of PRP gel on the upper jaw, the distance to the alveolar process in the most pronounced area of resorption of the gingival margin in the projection of the chewing teeth, on average, was $7.68 \pm 0.16 \mathrm{~mm}$, and its width was $16.15 \pm 0.14 \mathrm{~mm}$. On the lower jaw, such indicators were at the level of $8.54 \pm 0.13 \mathrm{~mm}$ and $13.76 \pm 0.16 \mathrm{~mm}$, respectively (at P1>0.05, P2>0.05) (Table 2). Comparing the values with the initial figures, we obtained the following results: the sagittal parameter of the alveolar process on the upper jaw increased by $+0.73 \mathrm{~mm}$, and the transversal one-by $+0.95 \mathrm{~mm}$.
On the lower jaw, the dimensions of the alveolar ridge were +1.31 $\mathrm{mm}$ and $+0.99 \mathrm{~mm}$, respectively.

Thus, in the 1st main group, one month after the treatment, there was a tendency to an insignificant $(\mathrm{P} 1>0.05)$ increase in the volume of periodontal tissues, probably due to the activation of the restorative function of the periosteum, which is due to the osteoinductive properties of the platelet concentrate of autoplasm.

Anthropometric measurements at 3, 6 and 12 months in postinjection period witnessed the decline, but the numbers still remained above baseline (when P1>0,05 P2> 0,05)

After 6 months, the height of a crest on the upper jaw meet was $7.23 \pm 0.13 \mathrm{~mm}$ and a width of $15.34 \pm 0.18 \mathrm{~mm}$. On the lower jaw, these indicators were $7.86 \pm 0.15 \mathrm{~mm}$ and $13.45 \pm 0.18$ $\mathrm{mm}$, respectively. Over the past period (from the first to the sixth months), the height of the process on the upper jaw decreased by $0.45 \mathrm{~mm}$, the width-by $0.81 \mathrm{~mm}$. On the lower jaw - by $0.68 \mathrm{~mm}$ and $0.9 \mathrm{~mm}$ (Table 2).

In the subsequent control period (12 months), a slight decrease in the parameters of the alveolar ridge of the jaws was observed, but the indicators retained their advantages in comparison with the baseline level. So, on the upper jaw in the area of molars and premolars (collectively), the height was $7.12 \pm 0.17 \mathrm{~mm}(+0.17$ $\mathrm{mm})$, and the width was $15.28 \pm 0.15 \mathrm{~mm}(+0.08 \mathrm{~mm})$. On the lower jaw, $7.34 \pm 0.14 \mathrm{~mm}(+0.11 \mathrm{~mm})$ and $13.45 \pm 0.18 \mathrm{~mm}$ $(+0.01 \mathrm{~mm})$, respectively. All the data have statistically unreliable differences in relation to the values of the control group and in comparison with the baseline level (P1>0.05, P2>0.05).

Thus, the results of studying the dynamics of changes in bone volume indices indicate a decrease in the activity of osteolytic processes in the alveolar bone and, accordingly, the achievement

Table 2. The average values of the height and width of the alveolar process in the projection of the premolars and molars of the upper and lower jaws (in $\mathrm{mm}$ ) in the 1st main group at different observation periods.

\begin{tabular}{|c|c|c|c|c|}
\hline \multirow[b]{2}{*}{ Measurement dates } & \multicolumn{2}{|c|}{ Upper jaw } & \multicolumn{2}{|c|}{ Low jaw } \\
\hline & $\begin{array}{c}\text { height to the } \\
\text { ridge }^{1}(\mathrm{~mm}) \\
\mathrm{n}=17 \\
\mathrm{M} \pm \mathrm{m}\end{array}$ & $\begin{array}{l}\text { ridge width } \\
\begin{array}{l}(\mathrm{mm}) \\
\mathrm{n}=17 \\
\mathrm{M} \pm \mathrm{m}\end{array}\end{array}$ & $\begin{array}{c}\text { height to the } \\
\text { ridge }^{1}(\mathrm{~mm}) \\
\mathrm{n}=17 \\
\mathrm{M} \pm \mathrm{m}\end{array}$ & $\begin{array}{c}\text { ridge width } \\
\begin{array}{c}(\mathrm{mm}) \\
\mathrm{n}=17 \\
\mathrm{M} \pm \mathrm{m}\end{array}\end{array}$ \\
\hline Before injection therapy $(\mathrm{n}=40)$ & $6.95 \pm 0.15$ & $15.20 \pm 0.17$ & $7.23 \pm 0.16$ & $13.44 \pm 0.19$ \\
\hline \multirow{3}{*}{ After 1 month $(\mathrm{n}=34)$} & $7.68 \pm 0.16$ & $16.15 \pm 0.14$ & $8.54 \pm 0.13$ & $14.43 \pm 0.14$ \\
\hline & $\mathrm{P}_{1}>0.05$ & $\mathrm{P}_{1}>0.05$ & $\mathrm{P}_{1}>0.05$ & $\mathrm{P}_{1}>0.05$ \\
\hline & $\mathrm{P}_{2}>0.05$ & $\mathrm{P}_{2}>0.05$ & $\mathrm{P}_{2}>0.05$ & $\mathrm{P}_{2}>0.05$ \\
\hline \multirow{3}{*}{ After 3 months $(\mathrm{n}=34)$} & $7.65 \pm 0.15$ & $15.54 \pm 0.18$ & $8.23 \pm 0.16$ & $13.76 \pm 0.16$ \\
\hline & $\mathrm{P}_{1}>0.05$ & $\mathrm{P}_{1}>0.05$ & $\mathrm{P}_{1}>0.05$ & $\mathrm{P}_{1}>0.05$ \\
\hline & $\mathrm{P}_{2}>0.05$ & $\mathrm{P}_{2}>0.05$ & $\mathrm{P}_{2}>0.05$ & $\mathrm{P}_{2}>0.05$ \\
\hline \multirow{3}{*}{ After 6 months $(n=34)$} & $7.23 \pm 0.13$ & $15.34 \pm 0.18$ & $7.86 \pm 0.15$ & $13.53 \pm 0.14$ \\
\hline & $\mathrm{P}_{1}>0.05$ & $\mathrm{P}_{1}>0.05$ & $\mathrm{P}_{1}>0.05$ & $\mathrm{P}_{1}>0.05$ \\
\hline & $\mathrm{P}_{2}>0.05$ & $\mathrm{P}_{2}>0.05$ & $\mathrm{P}_{2}>0.05$ & $\mathrm{P}_{2}>0.05$ \\
\hline \multirow{3}{*}{ After 12 months $(n=34)$} & $7.12 \pm 0.17$ & $15.28 \pm 0.15$ & $7.34 \pm 0.14$ & $13.45 \pm 0.18$ \\
\hline & $\mathrm{P}_{1}>0.05$ & $\mathrm{P}_{1}>0.05$ & $\mathrm{P}_{1}>0.05$ & $\mathrm{P}_{1}>0.05$ \\
\hline & $\mathrm{P}_{2}>0.05$ & $\mathrm{P} 2>0.05$ & $\mathrm{P}_{2}>0.05$ & $\mathrm{P}_{2}>0.05$ \\
\hline
\end{tabular}


of stable remission during chronic generalized periodontitis in presence of local injection therapy with PRP gel, which, in our opinion, is due to the osteoinductive effect of the autograft. The data of anthropometric measurements correlated with clinical indicators that corresponded to a pronounced positive dynamics of treatment.

In the second main group, 1 month after injection of the combination of PRP with Collapse $\mathrm{C}$, the sagittal and transversal dimensions $(\mathrm{M} \pm \mathrm{m})$ of the alveolar processes in the projection of premolars and molars on both jaws differed from the initial values $(\mathrm{P} 1<0.05)$ (Table 3). Thus, in the upper jaw, the height of the alveolar process increased by $0.93 \mathrm{~mm}(7.88 \pm 0.14 \mathrm{~mm})$, and the width by $2.05(17.25 \pm 0.14 \mathrm{~mm})$. On the lower jaw - by $1.09 \mathrm{~mm}$ $(8.32 \pm 0.14 \mathrm{~mm})$ and by $1.89(15.33 \pm 0.12 \mathrm{~mm})$. There was no statistically significant difference in comparison with the control group (except for the width of the alveolar process of the upper jaw, where $\mathrm{P} 2<0.05$ ) and the 1 st main group during this period of observations $(\mathrm{P} 2>0.05, \mathrm{P} 3>0.05)$.

3 months after treatment, the distance to the alveolar ridge on the upper jaw was $7.92 \pm 0.20 \mathrm{~mm}$, the width was $17.54 \pm 0.16$ $\mathrm{mm}$. On the lower jaw, the average linear dimensions were at the levels of $8.86 \pm 0.17 \mathrm{~mm}$ and $15.64 \pm 0.16 \mathrm{~mm}$, respectively. The obtained data significantly differed from the mean values of the initial level $(\mathrm{P} 1<0.05)$, the indicators in the control group $(\mathrm{P} 2<$ $0.05)$ and in the 1 st main group $(\mathrm{P} 3<0.05)$ (Table 3$)$.

In the period from the third month to the sixth, the levels of increase in the height and width of the alveolar ridge on the upper and lower jaws were still statistically significant differences (at $\mathrm{P} 1<0.05, \mathrm{P} 2<0.05, \mathrm{P} 3<0.05)$.

This trend was most pronounced by 12 months, when, in comparison with the baseline level, the height and width indicators on the upper jaw significantly increased $(\mathrm{P} 1<0.05)$ by $17.46 \%$ and $15.74 \%$, and on the lower jaw - by $22.43 \%$ and $18.3 \%$, respectively. When comparing the figures in the same observation period with the values in the control and in the 1st main groups, it is also possible to identify significant differences in favor of the 2nd main group $(\mathrm{P} 2<0.05$ and $\mathrm{P} 3<0.05)$. The alveolar process height index was $8.42 \pm 0.18 \mathrm{~mm}$, which is $19.72 \%$ more than in the control group and $15.44 \%$ more than in the 1 st main group. The width of the alveolar bone increased to the level of $18.04 \pm$ $0.14 \mathrm{~mm}(16.58 \%$ higher than the values of the control group and $15.3 \%$ higher than the 1 st main group). The height of the alveolar process of the lower jaw was $9.32 \pm 0.16 \mathrm{~mm}(25.11 \%$ more than in the control, with $\mathrm{P} 2<0.01$ and $21.25 \%$ more than in the 1 st main group) and the width was $16.45 \pm 0.19 \mathrm{~mm}(19.27 \%$ and $18.24 \%$, respectively).

The diagrams of the dynamics of the average anthropometric indicators of the height and width of the alveolar process in the projection of the premolars and molars of the upper and lower jaws in the comparison groups clearly show that the processes of preservation and restoration of bone structures were most pronounced in the 2nd main group (Fig. 1, 2, 3, 4). At the same time, there were significant differences in the alveolar bone volume in-

Table 3. The average values of the height and width of the alveolar process in the projection of the premolars and molars of the upper and lower jaws (in $\mathrm{mm}$ ) in the $2 \mathrm{nd}$ main group at different observation periods.

\begin{tabular}{|c|c|c|c|c|}
\hline \multirow[b]{2}{*}{ Measurement dates } & \multicolumn{2}{|c|}{ Upper jaw } & \multicolumn{2}{|c|}{ Lower jaw } \\
\hline & $\begin{array}{c}\text { height to the } \\
\text { ridge }^{1}(\mathrm{~mm}) \\
\mathrm{n}=17 \\
\mathrm{M} \pm \mathrm{m}\end{array}$ & $\begin{array}{c}\text { ridge width } \\
\text { (mm) } \\
\mathrm{n}=17 \\
\mathrm{M} \pm \mathrm{m}\end{array}$ & $\begin{array}{c}\text { height to the } \\
\text { ridge }^{1}(\mathrm{~mm}) \\
\mathrm{n}=17 \\
\mathrm{M} \pm \mathrm{m}\end{array}$ & $\begin{array}{c}\text { ridge width (mm) } \\
\mathbf{n}=17 \\
\mathrm{M} \pm \mathrm{m}\end{array}$ \\
\hline Before injection therapy $(n=40)$ & $6.95 \pm 0.15$ & $15.20 \pm 0.17$ & $7.23 \pm 0.16$ & $13.44 \pm 0.19$ \\
\hline \multirow{4}{*}{ After 1 month $(\mathrm{n}=34)$} & $7.88 \pm 0.14$ & $17.25 \pm 0.14$ & $8.32 \pm 0.14$ & $15.33 \pm 0.12$ \\
\hline & $\mathrm{P}_{1}<0.05$ & $\mathrm{P}_{1}<0.05$ & $\mathrm{P}_{1}<0.05$ & $\mathrm{P}_{1}<0.05$ \\
\hline & $\mathrm{P}_{2}>0.05$ & $\mathrm{P}_{2}<0.05$ & $\mathrm{P}_{2}>0.05$ & $\mathrm{P}_{2}>0.05$ \\
\hline & $\mathrm{P}_{3}>0.05$ & $\mathrm{P}_{3}>0.05$ & $\mathrm{P}_{3}>0.05$ & $\mathrm{P}_{3}>0.05$ \\
\hline \multirow{4}{*}{ After 3 months $(\mathrm{n}=34)$} & $7.92 \pm 0.15$ & $17.54 \pm 0.16$ & $8.86 \pm 0.17$ & $15.64 \pm 0.16$ \\
\hline & $\mathrm{P}_{1}<0.05$ & $\mathrm{P}_{1}<0.05$ & $\mathrm{P}_{1}<0.05$ & $\mathrm{P}_{1}<0.05$ \\
\hline & $\mathrm{P}_{2}<0.05$ & $\mathrm{P}_{2}<0.05$ & $\mathrm{P}_{2}<0.05$ & $\mathrm{P}_{2}<0.05$ \\
\hline & $\mathrm{P}_{3}<0.05$ & $\mathrm{P}_{3}<0.05$ & $\mathrm{P}_{3}<0.05$ & $\mathrm{P}_{3}<0.05$ \\
\hline \multirow{4}{*}{ After 6 months $(n=34)$} & $8.33 \pm 0.16$ & $17.89 \pm 0.17$ & $9.26 \pm 0.18$ & $16.23 \pm 0.15$ \\
\hline & $\mathrm{P}_{1}<0.05$ & $\mathrm{P}_{1}<0.05$ & $\mathrm{P}_{1}<0.05$ & $\mathrm{P}_{1}<0.05$ \\
\hline & $\mathrm{P}_{2}<0.05$ & $\mathrm{P}_{2}<0.05$ & $\mathrm{P}_{2}<0.05$ & $\mathrm{P}_{2}<0.05$ \\
\hline & $\mathrm{P}_{3}<0.05$ & $\mathrm{P}_{3}<0.05$ & $\mathrm{P}_{3}<0.05$ & $\mathrm{P}_{3}<0.05$ \\
\hline \multirow{4}{*}{ After 12 months $(n=34)$} & $8.42 \pm 0.18$ & $18.04 \pm 0.14$ & $9.32 \pm 0.16$ & $16.45 \pm 0.19$ \\
\hline & $\mathrm{P}_{1}<0.05$ & $\mathrm{P}_{1}<0.05$ & $\mathrm{P}_{1}<0.05$ & $\mathrm{P}_{1}<0.05$ \\
\hline & $\mathrm{P}_{2}<0.05$ & $\mathrm{P}_{2}<0.05$ & $\mathrm{P}_{2}<0.05$ & $\mathrm{P}_{2}<0.05$ \\
\hline & $\mathrm{P}_{3}<0.05$ & $\mathrm{P}_{3}<0.05$ & $\mathrm{P}_{3}<0.05$ & $\mathrm{P}_{3}<0.05$ \\
\hline
\end{tabular}

Notes:

1 - the distance from the conditional line drawn through the occlusal surfaces of the teeth to the crest of the alveolar process in the area of maximum gum recession; $\mathrm{P}_{1}$ - the reliability of differences with the indicator before treatment;

$\mathrm{P}_{2}$ - the reliability of differences with the same indicator of the control group;

$\mathrm{P}_{3}-$ the reliability of differences with the same indicator of the 1 st main group. 
Figure 1. Dynamics of changes in the average anthropometric indices of the height of the alveolar process in the projection of the premolars and molars of the upper jaw in the comparison groups.

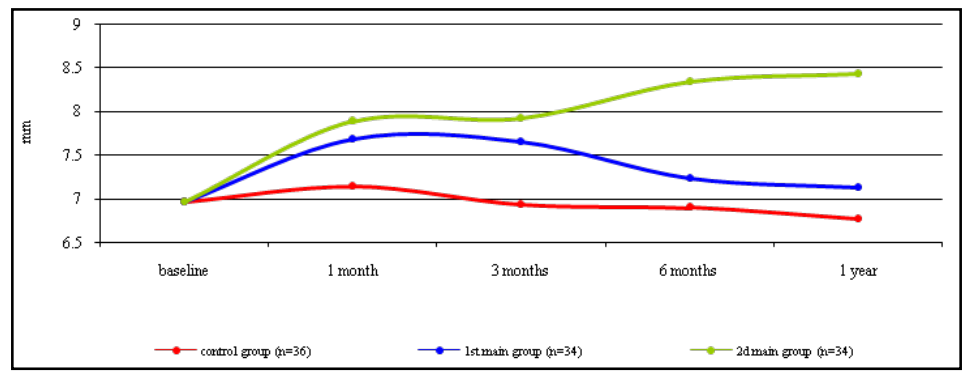

Figure 2. Dynamics of measurements of the average anthropometric parameters of the width of the alveolar process in the projection of the premolars and molars of the upper jaw in the comparison groups.

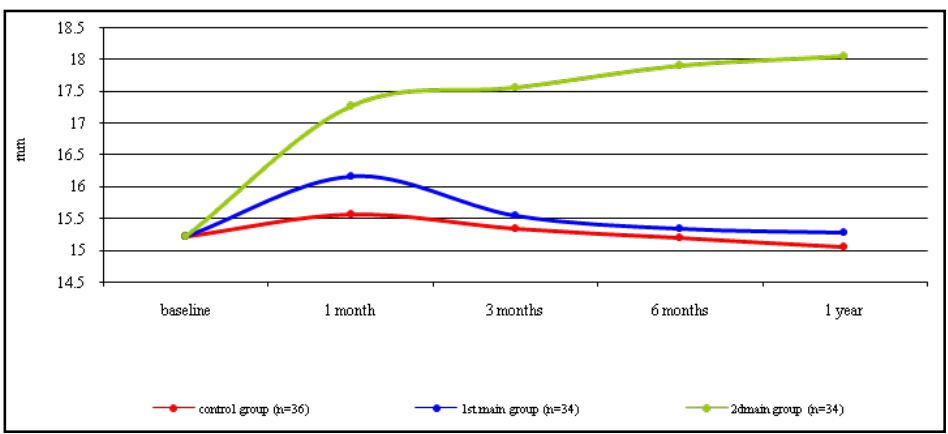

Figure 3. Dynamics of changes in the average anthropometric indices of the height of the alveolar process in the projection of the premolars and molars of the lower jaw in the comparison groups.

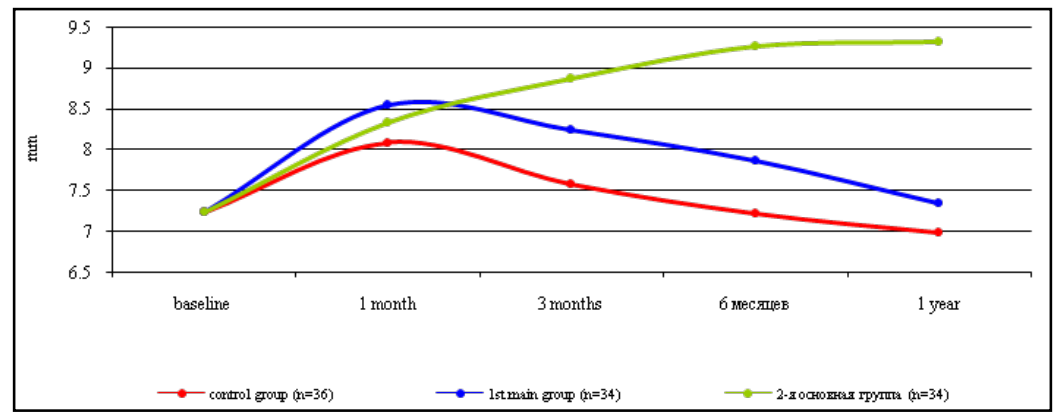

Figure 4. Dynamics of the average anthropometric parameters of the width of the alveolar process in the projection of the premolars and molars of the lower jaw in the comparison groups.
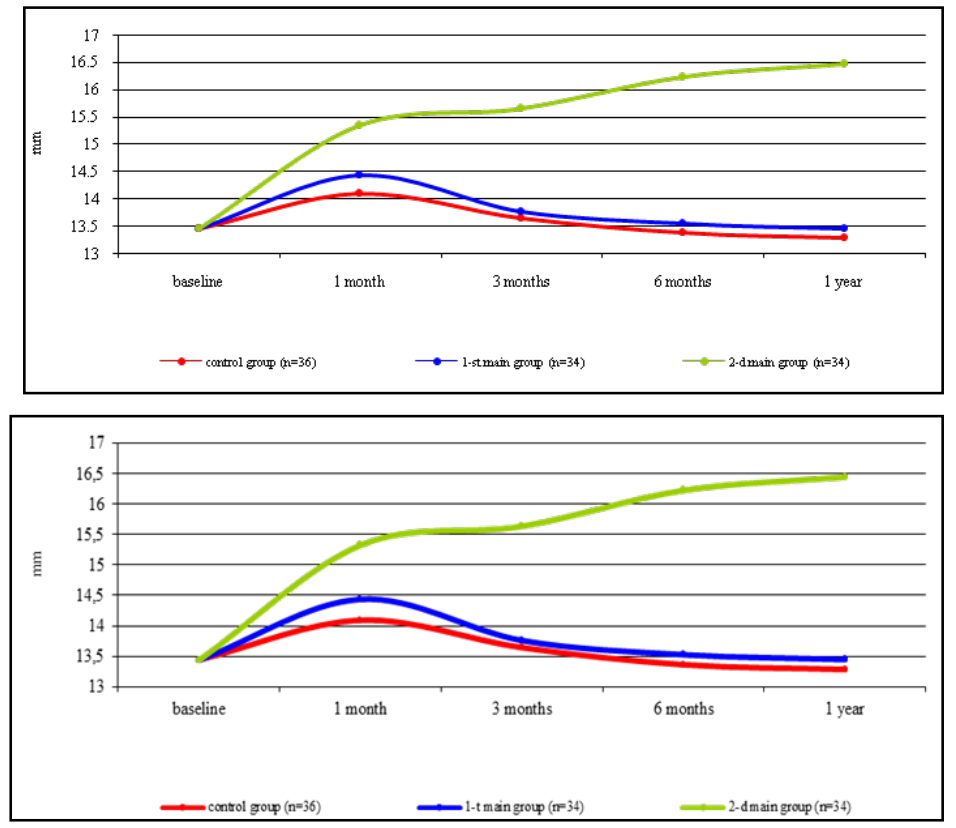
dicators by the 30-day observation period (P1<0.05), then they continued their growth by the $3 \mathrm{rd}$, 6th and 12 th months $(\mathrm{P} 1<$ $0.05, \mathrm{P} 2<0.05, \mathrm{P} 3<0.05)$. In our opinion, the positive osteoplastic therapeutic effect detected in patients in this group is due to the complementary properties of PRP-gel and the drug Collapan C, which together demonstrate osteoinductive and osteoconductive properties, manifested in presence of the release of silver ions, which has a local antiseptic and anti-inflammatory effect. All this, together, creates optimal conditions for preserving and restoring the volume of the alveolar bone.

It should be noted that patients in the I-th main group also had a positive result, where, despite the absence of a noticeable increase in bone tissue, its volume was preserved (Fig. 1, 2, 3, 4), this is explained by the pronounced osteoinductive and immunocorregulating properties of autoplasm with an increased platelet content. In patients in the control group, the process of gradual decrease in the anthropometric parameters of sagittal and transversal parameters continued, which, in general, is typical for chronic generalized periodontitis duration, accompanied by a constant loss of the alveolar bone (Fig. 1, 2, 3, 4), that is, the positive therapeutic result was short-term and did not have a long-term effect.

The data of anthropometry are confirmed by the results of X-ray examination of the alveolar processes in the comparison groups.

\section{Conclusion}

The results of jaw anthropometry confirm a higher efficiency of treatment of patients in the main groups, where local inflammatory and atrophic reactions subsided due to injectable local therapy with osteoplastic materials with osteoinductive and osteoconductive properties (main group 1) and the volume of lost alveolar bone was partially restored (main group 2). At the same time, the reliability of differences in the height and width of the alveolar process was traced from the 3rd to the 12th months of observations.

\section{References}

[1]. Achkasova EE, Bezuglov EN, Ulyanov AA. Use of autoplasma enriched with platelets in clinical practice. Biomedicine.2013; 4: 46-59.

[2]. PertungaroPS. The use of platelet-rich plasma with growth factors (autogenic platelet gel) to improve the healing of hard and soft tissues during bone buildup in the pneumatized sinus area. DENTAL VFRKET.2003;1: 12-16.

[3]. Danilevsky NF, Borisenko AV. Periodontal diseases, K,Zdorov'ya.2000.

[4]. Pavlenko AV, BugorkovaIA.The use of osteoplastic materials and plateletrich plasma in order to increase the effectiveness of flap operations in the treatment of generalized periodontitis. Modern dentistry.2006; 3: 45-48.

[5]. Robustova TG. Dental implantation (surgical aspects), Monograph.M, Medicine.2003.

[6]. Salaimeh RH. Comprehensive assessment of the effectiveness of the use of brefo-ceramic plastic material in the prevention of postoperative atrophy of the alveolar process. dis. candidate of medical Sciences: 14.01.22. ,Simferopol.2002.

[7]. Bezrukov SG, Gerasimenko OV, Saenko TS. Results of subperiosteal injection of osteoplastic materials into the alveolar part of the jaw of experimental animals. Crimean Journal of Experimental and Clinical Medicine.2018; $8(1): 11-15$.

[8]. Maksyutin IA, Mukhaev KhX, EfimovYuV. et al. The use of autogenic platelet gel in the treatment of near-root cysts. Medical alphabet.2013; 3(15): 44-45.

[9]. Yanushevich OO, Runova GS, Vybornaya EI. The use of osteotropic materials in the treatment of periodontal diseases by surgical methods. Medical Council.2011;7/8: 101-103.

[10]. Lenev VN, LaipanovaFM.The use of osteoplastic materials inDentistry. Scientific Almanac of Medical Sciences.2016;5(19):292-297. 